\title{
UN VERSO DE VIRGILIO PIÑERA EN LA CAPACIDAD CREADORA DE REINALDO ARENAS: DE "LA ISLA EN PESO" A EL COLOR DEL VERANO
}

\author{
Humberto López Cruz
}

\section{(c) $($ () $\odot$}

Esta obra está bajo una licencia Creative Commons

Reconocimiento-No Comercial-Sin Obra Derivada 



\title{
UN VERSO DE VIRGILIO PIÑERA EN LA CAPACIDAD CREADORA DE REINALDO ARENAS: DE "LA ISLA EN PESO" A EL COLOR DEL VERANO
}

\author{
A VERSE BY VIRGILIO PINERA IN THE CREATIVENESS OF \\ REINALDO ARENAS: FROM "LA ISLA EN PESO" TO EL COLOR \\ DEL VERANO
}

Humberto López Cruz

\begin{abstract}
RESUMEN
Este trabajo pretende un acercamiento a El color del verano, de Reinaldo Arenas, a través de un posible desplazamiento poético. El escritor cubano comenta un detalle en su autobiografía que pudiera apuntar hacia un laberinto de permutaciones textuales donde se establecería una conexión, quizás inapelable, con un verso del imperecedero poema de Virgilio Piñera "La isla en peso". El estudio se encamina hacia un retroceso creativo en el que se sugiera el origen de la idea; o sea, la fuente de donde brotara un fragmento fundamental de la trama de El color del verano. Por supuesto, habría que remontarse al canónico poema, publicado en 1943, con la isla y sus habitantes como protagonistas, para comprender la narrativa hiperbólica de Arenas. El paralelo comienza a delinearse entre ambos textos puesto que en uno se canta poéticamente a la isla en peso; en el otro, el peso de la isla hace que, sin plataforma, se hunda en el mar. La idea modificada toma forma y lo que fuera un verso en el poema de Piñera se convierte en el desenlace de la novela de Arenas. Palabras clave: Arenas-Reinaldo, Piñera-Virgilio, historia, permutación textual, isla.
\end{abstract}

\begin{abstract}
This work attempts to approach Reinaldo Arenas' The Color of Summer by means of a possible poetic displacement. In his autobiography, the Cuban writer makes subtle comments that point towards a labyrinth of textual permutations that, perhaps, connect with a verse from Virgilio Piñera's timeless poem "The Whole Island." This essay, thus, creatively retraces the steps that lead to the origin of the novel's idea, that is the seed from which The Color of Summer sprouted. In order to understand Arenas' hyperbolic narrative, one must first return to Piñera's canonical poem, published in 1943, which portrayed the island and its inhabitants as protagonists. A comparison reveals a parallel that begins to delineate itself between both texts: the poem singing about the island in its totality and the prose depicting how the weight of the foundation-less island forces it to sink into the sea. Ultimately, this modified idea from a verse in Piñera's poem becomes the outcome of the novel by Arenas.
\end{abstract}

Key words: Arenas-Reinaldo, Piñera-Virgilio, history, textual permutation, island.

Dr. Humberto López Cruz. University of Central Florida. Profesor de literatura latinoamericana y Director del Departamento de Lenguas Modernas. Orlando, Estados Unidos.

Correo electrónico: hlopez@ucf.edu

Recepción: 30- 09- 2014

Aceptación: 20- 10- 2014 


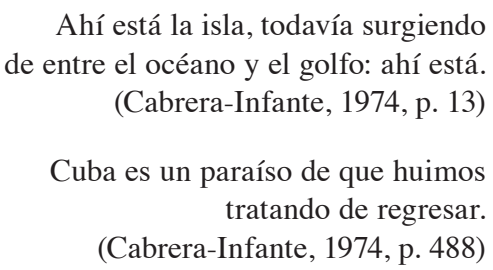

\section{Introducción}

Reinaldo Arenas (1943-1990) comenta un detalle en su autobiografía que pudiera apuntar hacia un laberinto de permutaciones textuales donde sería posible establecer una conexión, quizás inapelable, con un verso del imperecedero poema de Virgilio Piñera (19121979), "La isla en peso". Es menester subrayar que la idea proviene del propio Arenas, quien reconoce en un capítulo dedicado a Piñera cómo este le revisaba el trabajo, admitiendo además que "siempre le estaré agradecido a Virgilio por aquella lección, más que literaria, de redacción” (Arenas, 1992, p. 105); un poco más adelante, en el mismo apartado, reconoce que el poema antes mencionado "es una de las obras maestras de nuestra literatura" (1992, p. 106). Sin embargo, antes de pasar a discutir la sugerida implicación, es necesario dejar sentadas ciertas pautas que contribuirán no tan solo a desensamblar unos fragmentos que comparten un origen común sino a emplazar una visión unificadora de aspectos de la obra de Arenas donde el recuerdo de Piñera, cual tributo literario, esté presente.

La lectura de una autobiografía presenta, de por sí, un cuestionamiento posterior en el que se juzga la veracidad de los datos presentados. Se ha dicho que "la autobiografía está inseparablemente unida a la concepción del yo", para añadir, "la forma en la que el hombre concibe la naturaleza del yo determina en gran medida tanto la forma como el proceso de la escritura autobiográfica" (Weintraub, 1991, p. 25). ${ }^{1}$ En Antes que anochezca no se observa ninguna indicación que pudiera sugerir que algún texto de Piñera hubiese servido de inspiración, o continuación textual, para su autor. Arenas sí menciona que sus novelas, publicadas en el extranjero residiendo él en Cuba, eran "textos irreverentes" (1992, p. 143) ${ }^{2}$ y pasa a dilucidar el valor literario de los mismos y los éxitos cosechados. ${ }^{3} \mathrm{La}$ escritura se concentra en el poder creativo, y creador, del yo narrador abundando en cómo el escritor se percibe dentro de la sociedad que lo acorrala. Según este, en El color del verano, "mi generación [...] con excepción de mí mismo no ha podido producir un autor notable" (Arenas, 1990, p. 247). Ahora resta decidir el grado de aceptación que adopte el lector y que, en su momento, autentique el enunciado biográfico.

Hay, a su vez, que dejar sentadas ciertas bases que pueden tacharse de imprescindibles para una mejor aproximación a la trama de El color del verano. El narrador aparece no tan solo como el relator omnisciente bajo su propio nombre sino también bajo el seudónimo de Gabriel y en la mayoría de las veces como la Tétrica Mofeta. ${ }^{4}$ Esta complejidad contribuye a una fluidez conectiva y logra que cada personaje plantee la faceta que quiere revelar de sí mismo, hecho que conlleva a crear un estado conspiratorio con quien tiene que incorporarse a la relación que el autor persigue. ${ }^{5}$ Umberto Eco apunta que "in cases of texts conceived for a general audience [...] the sender and the addressee are present in the text, not as mentioned poles of the utterance, but as 'actantial roles' of the sentence" $(1984$, p. 10). De aquí que se deba responder al llamado efectuado y acentuar el estado de complicidad iniciado por Arenas. La triple interrelación, autor-texto-lector, se implanta no solo para una satisfactoria comunión 
sino para el establecimiento de una relación directa entre la tríada, permitiendo así una apertura a una mayor cantidad de posibilidades discursivas y argumentos interpretativos. En la novela, la pluralidad referencial del autor-narrador demanda la incorporación del lector para identificar sus fases y, al mismo tiempo, capturar la esencia de cada una de ellas y el papel que desempeñan en la escritura.

Es notable recordar que en el final de la introducción de su autobiografía, Arenas invoca a Piñera, en una súplica autoritaria, demandando tres años más de vida (1992, p. 16); el escritor anhela ganarle temporalmente la batalla al sida para poder concluir su obra literaria. Al parecer, Virgilio, devenido cómplice involuntario, concede la demanda, pero no como mentor sino que según Arenas "fue mi profesor universitario, además de mi amigo" (1992, p. 105). Sin que se sospeche una posible apropiación textual hay, a su vez, que aducir que los amigos de Arenas lo llamaban "la esponja" ya que "absorbía ritmos y fragmentos de lo que leía cualquiera y luego lo traía incorporados a sus obras" (Abreu, 1998, p. 100); por otra parte, otro de sus compañeros de tertulias recuerda que "a veces en la exaltación, se nos escapaban ideas que otro aprovechaba. Rey era un rey en eso. Raptaba la idea con su estilo y la hacía suya sin remedios" (Abreu-Felippe, 2001, p. 186). Quizás no fuere entonces una intuición descabellada presuponer la existencia de una articulación de creatividad literaria entre el profesor y el alumno donde, tras sabia metamorfosis imaginativa, resulte en que ideas acogidas con esmero y selectividad puedan hallarse en la totalidad de la obra de Arenas.

Este trabajo pretende un acercamiento a El color del verano, cuarta novela de la pentagonía ${ }^{6}$ que fue considerada "fundamental en el ciclo" (Arenas, 1992, p. 12) y sobre la cual el propio Arenas estampó que "se desarrolla en un gran carnaval en el que el pueblo logra desprender la Isla de su plataforma insular y marcharse con ella como si fuera un bote" (Arenas, 1992, p. 15). En verdad, el estudio se encamina hacia un retroceso creativo en el que se sugiera el origen de la idea; o sea, la fuente de donde brotara una parte integral de la trama de El color del verano. Por supuesto, habría que remontarse al canónico poema, publicado en $1943,{ }^{7}$ con la isla y sus habitantes como protagonistas, para comprender la narrativa hiperbólica de Arenas. Como comienza a escribirla estando en el hospital durante los últimos años de su vida, debemos presuponer que fue completada dentro del período otorgado por Piñera ante la demanda del moribundo suplicante. El paralelo comienza a delinearse entre ambos textos puesto que en uno se canta poéticamente a la isla en peso; en el otro, el peso de la isla hace que, sin plataforma, se hunda en el mar. La idea modificada toma forma y lo que fuera un verso en el poema de Piñera se convierte en el desenlace de la novela de Arenas.

Antes de proceder con los puntos que corroborarían una supuesta intertextualidad en lo que a la permutación de textos concierne, es recomendable pausar y visitar el poema de Piñera. "La isla en peso" ha sido considerada como "un aporte formidable a la lírica cubana" (Jiménez, 2012, p. 193) y un "extraordinario texto" (Quintero-Herencia, 2012, p. 213). En su juicio, Rafael Rojas agrega que "está concebido como una larga peregrinación de los insulares hacia la noche, donde podrán liberarse del agua, de la luz y de Dios" (2002, p. 255). No obstante, se podría añadir que la totalidad de la entrega poética es un continuo conversatorio donde se persigue una ruptura consigo mismo y con los fantasmas que han plagado la historia de Cuba; es un triunfo para la poesía como género y para el individuo en su autodeterminación. A pesar del desconocimiento general al que alude Antón Arrufat de la poética de Piñera (2002, p. 54), "La isla en peso" se afianza en su escritura para insuflar a la literatura cubana el atrevimiento necesario con el que figurar entre sus homónimas latinoamericanas. La isla, como personaje, 
reconoce su trayectoria y asume una realidad que incluye, desde un anticipado fatalismo, hasta una redención por medio de sus habitantes. Para esta propuesta, es imprescindible traer a colación la conclusión de Miguel Ángel De Feo quien, en su enfrentamiento con el poema, sostiene que "el peso de la isla es una alegoría de la discordia entre la voz poética y su entorno -entre el pensar y el ser- que conduce a la enajenación y a la desesperación" (2012, p. 236). Este aserto conforma una visión apocalíptica de unos versos que se repiten, no en derrota ni en la sugerida negación del sujeto sino anticipando la victoria de la aceptación colectiva de una nación. Cabría replantearse si Piñera no persigue, además, una regeneración singularizada y aplicada a su propia persona aunque revierta el discurso poético con las coordenadas geográficas de su isla. Es muy cierto que se advierte la insinuada enajenación y, más fácil aún sería ver, la desesperación del individuo ante lo inexorable; de por sí, esto situaría al lector dentro de la obra de un Arenas libre y desprovisto de ataduras restrictivas que pudieran dejar secuelas de omisión en su texto. Si bien hay que considerar que el autor está agonizante en un hospital de New York con agujas en las manos (Arenas, 1992, p. 12) y, por supuesta gracia de Piñera, robándole tiempo a la muerte, qué mejor manera de rendir tributo al maestro que vanagloriándose de su acostumbrada postura. Este es un hecho conocido, pues declaró que "yo no concibo la libertad sino como caos" (Ette, 1992, p. 85), desgarramiento tal que trasciende a y se identifica con su narrativa.

\section{Un engarce literario ${ }^{8}$}

hay que morder, hay que gritar, hay que arañar (Piñera, 2000b, p. 38)

Este precedente facilita la mutación que llevaría a El color del verano pensando en "La isla en peso" como vocación y aprobación hacia y de una agresividad social que va a desarrollarse a plenitud en esta cuarta novela de la pentagonía. Este ensayo encuentra su zócalo en un verso, epígrafe de esta sección, "hay que morder, hay que gritar, hay que arañar" (2000b, p. 38), fundamental en toda su intensidad para lograr la fusión Arenas-Piñera que justifique una intersección explícita entre ambos. Arenas, quien fue a Estados Unidos a gritar [la cursiva es agregada] (Arenas, 1992, p. 309), va a hacer suyos los verbos que su profesor le facilitara; al mismo tiempo, va a desarrollar la idea de la isla condenada que aunque cuente con "el amor de un pueblo" (Piñera, 2000b, p. 49) no puede evadir que al final se hunda en el mar "entre un fragor de gritos de protesta" [la cursiva es agregada] (Arenas, 1990, p. 442). La sombra del poema se extiende sobre la novela dejando pistas inequívocas que auguran descubrir otros puntos en común.

Es inevitable registrar que El color del verano contiene capítulos relacionados, en su totalidad, con Virgilio. El primero, más oportuno y titulado "Virgilio Piñera lee sus poemas efímeros" (Arenas, 1990, pp. 127-132), conecta directamente con el verso que ocupa la esencia de este trabajo. ${ }^{9}$ El texto refiere que el poeta lee composiciones inéditas ante una selecta concurrencia de la que Arenas es parte bajo la personalidad de una de sus encarnaciones: la Tétrica Mofeta. La selección poética no podía ser más sugestiva porque, además de juzgarse como un "poema magistral" y "poema perfecto" (Arenas, 1990, p. 128), se alega "el dolor íntimo de cada ser humano y el dolor de la humanidad entera", para continuar con uno que "recorría, entre tambores, y todo tipo de himnos, la isla" (Arenas, 1990, pp. 128 y 130). Los epítetos afortunados con que los críticos alaban "La isla en peso" se consolidan en el juicio 
de Arenas; sin embargo, a pesar de ser un poema perfecto y magistral es el propio Piñera, en la novela, el que lo lanza a las llamas apenas concluye la lectura: "sí, lloren, griten [...], Pero, óiganlo bien, estos poemas son los originales, no hay copias. Y esta noche, a medida que los vaya leyendo los iré quemando" [la cursiva es agregada] (Arenas, 1990, p. 129). La supuesta destrucción de los versos; es decir, la originalidad del poeta o, en su defecto, la voz del individuo marginado, abarca una dimensión superior puesto que anticipa una inminente catástrofe concerniente al destino del país; Cuba perece pasto de las llamas. La isla del poema, única, se observa transmutada en la nación cubana de Arenas; sus tribulaciones, individual y colectiva, enfilan hacia la tragedia.

La consternación por parte de los oyentes ante las lecturas poéticas del maestro deriva en un grito de terror que sale de la boca de los que escuchan [la cursiva es agregada] (Arenas, 1990, p. 129). Aquí Piñera, a través de una lectura apócrifa, subraya la necesidad de gritar; Arenas, en gratitud, calca la exhortación que porta "La isla en peso", puesto que quienes se habían deleitado con lecturas sobre una isla imperecedera muestran con su reacción un rechazo fusionado a un incipiente terror ya que "los gritos de pena de toda la audiencia fueron alaridos de espanto"; además, "se arañaban la cara", no pudiendo evitar "un aullido unánime"; escándalo tal que la concurrencia temió haber sido descubierta tras la ejecución conjunta del verbo profético y llegó a sospecharse que "¡ese grito sí tiene que haber sido escuchado por el Comité de Defensa!" [la cursiva es agregada] (Arenas, 1990, pp. 128-130). ${ }^{10}$ Y un aterrado Virgilio desaparece de la tertulia, tal como los versos efímeros recién recitados y consumidos por el fuego. Christopher Winks supone, acertadamente, que Arenas "convierte la evanescencia en elemento central de una contraestrategia de movilidad casi improvisatoria" (2008, p. 107); a pesar de ello, es factible concebir otra posibilidad: Piñera puede llevarse consigo su obra, su asumido silencio y su miedo, mas no la totalidad de su destruido legado literario puesto que ya ha sido absorbido por la imaginación de Arenas.

De la misma manera que "La isla en peso" recurre a la historiografía cubana, Arenas titula ciertos capítulos "La historia", los cuales ambicionan reescribir la nación y sus habitantes, ${ }^{11}$ aunque en una dictadura solo la palabra del sátrapa constituya la única voz, la historia oficial. ${ }^{12}$ Es harto sabido que todos estos eslabones de una obra circular, como el autor denomina El color del verano (Arenas, 1990, p. 249), comienzan por "Ésta es la historia de una isla..." (Arenas, 1990, pp. 123, 163, 204, 327 y 442); se puede presuponer, sin andar muy descaminados, que la expresión pretende alejarse de la realidad del momento para acercarse, con cautela, a la isla de Virgilio. Por consiguiente, es natural conceptualizar la incorporación de sucesos que intentarán colaborar en la inserción de las cuentas de un collar, convertidas en capítulos, de una circularidad novelística antes mencionada. La historia de Arenas revierte a un pueblo hastiado que "araña la tierra" [la cursiva es agregada] (Arenas, 1990, p. 163); a su vez, en su desesperación decide por unanimidad "roer la plataforma insular de la isla hasta separarla de su base" sospechando que "una vez que la isla cambiase de lugar encallaría cerca de algún continente, de alguna tierra firme y libre" [la cursiva es agregada] (Arenas, 1990, p. 123). Esta resolución del narrador de utilizar arañar y coadunar la acción con la tierra, sinónimo en este caso de isla, remonta a los albores de su autobiografía, justo tras concluir la introducción (Arenas, 1992, pp. 9-16) y agradecer a Virgilio la prórroga concedida a su existencia: "pasaba la lengua por la tierra. El primer sabor que recuerdo es el sabor a tierra. Comía tierra...” (Arenas, 1992, p. 17). No será difícil figurar que las mordidas de Arenas encontrarían eco en el poema del maestro Piñera y repercutirían en su novela regurgitando, literariamente, la tierra implicada para volverla a ingerir por medio de sus personajes. 
La mencionada concepción del yo autobiográfico comienza con los primeros recuerdos del autor dentro de su espacio rural. Si se admite, y refiriéndose a Arenas, que "la lectura de su autobiografía implicaría además la reflexión sobre las diversas construcciones que él mismo hizo de su identidad a lo largo de toda su obra" (Flores, 2008, p. 127), entonces comer tierra es una premonición catatónica que solo podrá satisfacerse tras una ingestión, aunque figurada, del suelo patrio. En El color del verano, el autor va a denominar roedores a aquellos que, opuestos al régimen que los asfixia, pretenden socavar la plataforma de la isla como acto contestatario que desafía el poder. En el texto, el simple acto de roer constituye una posición frontal ante una autocracia que no disculpa ni olvida cualquier disensión de la postura oficial: "al que se le calificaba de roedor se le intentaba eliminar al instante" (Arenas, 1990, p. 124). La función de los personajes de Arenas adosados al verso de Piñera deben, al mismo tiempo, unirse a la tierra para lograr una comunión directa; o sea, comulgar con el tropo escogido y, paradójicamente, destruirlo:

\footnotetext{
decidieron tácitamente roer la plataforma insular de la isla hasta desprenderla de su base [...] Claro, el desprendimiento de la isla de su plataforma insular no era cosa fácil; la plataforma, precisamente por su condición de plataforma era una roca durísima. [...] había que escarbar debajo del agua [...] con incesantes y clandestinas zambullidas todo el pueblo comenzó a roer la plataforma insular de la isla de Cuba (Arenas, 1990, pp. 123-124)
}

En esta fusión de citas, la plataforma adquiere el recurso metonímico de un país, de una Nación, aunque para el propósito de esta lectura sea acertado percibirla como el peso de la isla entera. Jesús Jambrina condensa la crítica que del poema efectuara, en su momento, Cintio Vitier para explicar que es "convertirse en un modelo para una comprensión diferente del país, diseñando el mapa de la historia" (2012,p. 113). No es, entonces, un plan descabellado consentir que El color del verano ostente cinco capítulos rotulados "La Historia" dentro de una novela que va a asentarse en fundamentos históricos, incluyendo el literario, para establecer un puente maestro-alumno que justifique la presencia de Virgilio en la creatividad de Arenas.

El peso de la isla, literalmente hablando, tiene que recaer sobre una narrativa subordinada a unos parámetros de inserción textual que cumpla la permutación, y a la vez recreación, de un solo verso, escogido este, dentro de un largo poema. Al mismo tiempo, el verso en cuestión tiene que convertirse en zócalo, suplantando el término de plataforma, para constituirse en el sostén del andamiaje creativo de El color del verano. El hecho que la novela haya sido asimilada como un "universo descentrado y móvil" (Esteso-Martínez, 2002, p. 220) coincide con enunciado liberador del poema y no impide una fuga masiva del individuo, poética y real, en el instante que se le rinde el adiós postrero a Virgilio. La historia está siendo reescrita y sería aconsejable añadir el factor ironía histórica como complemento discursivo. ¿Qué mejor momento para que los personajes de Arenas triunfen en su empeño y desprendan la isla para destruir el sistema que los maniata? Piñera tiene que estar presente textualmente para lograr el engarce verso-novela; la reproducción de la idea, absorbida por la metafórica esponja areniana, ha triunfado en la intersección de una creatividad consumada. En El color del verano, el féretro conteniendo los restos mortales del poeta no es depositado en tierra, sino cae en el mar; la plataforma insular ha sido separada de su base y solamente hay agua bajo la corteza terrestre. "La maldita circunstancia del agua por todas partes" (Piñera, 2000b, p. 37) no podía ser más oportuna y, como oposición binaria, bendecida: 
En la novela, la isla cubre el ataúd de Virgilio; más importante, encubre su palabra para protegerla, y honrarla, en la urna natural que provee la nación cubana en su colectividad. El canto del poeta se verá transmutado en una prosa que destruye para construir, que se lamenta para celebrar la victoria de una libertad en ciernes y, sin dudas, el triunfo de un poema que signa un antes y un después en la poesía cubana. No podría ser más apropiado que intercalar como colofón investigativo las palabras del propio Arenas sobre "La isla en peso":

[...] es el drama de la intemperie y la persecución, la desesperación, el vacío y la asfixia de todo un pueblo.
Inspiración y documento, imagen y ritmo, furor y lucidez; se trata de una suerte de frenética espiral
donde, entre vertiginosas dentelladas, se habla a la vez de nuestra tradición y de nuestra historia, se
explica y se replica, se maldice e invoca. Obra totalizadora, resume a través de la indignada, amorosa y
conmovida memoria del poeta, la historia de nuestro país. [la cursiva es agregada] (Arenas, 2001, p. 142) ${ }^{13}$

Este testimonio facilita, aún más, el propósito de un fragmento imprescindible de El color del verano; la sugerencia de la conexión textual se apoya en sólidos pilares que autentican homenaje póstumo al maestro. El énfasis resaltado en la cita precedente obedece al establecimiento de un vínculo literario. Recuérdese que Virgilio es uno de los primeros resucitados para participar el acto de repudio gubernamental por la fuga de la Avellaneda. La carajicomedia con que comienza El color del verano (Arenas, 1990, pp. 11-62) no omite la presencia del poeta; de hecho, la resalta para afirmar, por un lado, la marginación que sufría Piñera en la isla y, segundo, el reconocimiento que haría Arenas y que ya se perfila en la novela. El grito profético del poeta se advierte en el parlamento que le dirige a la Avellaneda: "mientras secretamente por Ti mi copa alzo / a toda voz debo condenarte. No permitas que te asfixie la maldita circunstancia del agua por todas partes" (Arenas, 1990, p. 17). Desde la óptica de este ensayo constituye el incentivo requerido, al reproducir en el subrayado el verso con que comienza "La isla en peso", a la creatividad del joven escritor ante su "profesor universitario" además de su "amigo" (Arenas, 1990, p. 105).

La asfixia aludida por Arenas en su ensayo crítico ha traspasado los textos para instalarse en la cuarta novela de su pentagonía y aparecer en la advertencia de Piñera; a su vez, acepta el consejo y no permite que la maldita circunstancia ahogue a sus personajes, al menos no por ahora, haciendo que su conglomerado roedor desarrolle "potentes pulmones que le permitían estar bajo el agua hasta casi una hora" (Arenas, 1990, p. 124). La constante urgencia de reescribir la historia en El color del verano podría ser un atenuante edificador para un individuo que agoniza en un hospital bajo la sombra tutelar del que considerara su maestro. En otras palabras, el leitmotiv de estos capítulos llamados históricos, por no encontrar un mejor término, podría sugerir una asociación del discurso narrativo con el poema de Virgilio; entiéndase una posible continuación. "La isla en peso" sería vista como inspiración y antesala de los instantes en que los ciudadanos roen la tierra; es decir, se llenan la boca con fragmentos de Cuba: "Los pueblos y sus historias en boca de todo el pueblo" (Piñera, 2000b, p. 41) para consumar el hado de destrucción. La hipérbole sobre la dentición engendrada en los "dientes prominentes" (Arenas, 1990, p. 124) de los roedores se transfigura en las "catorce hileras de dientes irreprochables" (Arenas, 1990, p. 125) de Tiburón Sangriento. La isla desprendida de su autenticidad geográfica insiste en legar su historiografía y aunque "enseñando los dientes" (Piñera, 2000b, p. 49) los tiburones destruyan a dentelladas la contrapartida de la postura oficial, la resistencia ofrece suficiente credibilidad para que sea tomada en consideración; el recuerdo de Virgilio es latente y el simbólico grito, compartido por los dos escritores, es espacio común de toda una generación que pugna por no ser olvidada. Arenas persiste en su compromiso de 
contar un "mundo en que si no lo escribo se perderá fragmentado en la memoria de los que lo conocieron" (Arenas, 1990, p. 249). Es viable que se lea como un narrador derrotado, mas no destruido, y quien comprende, en la penúltima página de El color del verano, que tiene que comenzar, una vez más, a reescribir su versión de la historia.

\section{Conclusión: comunión unificadora}

yo vine aquí a gritar

(Arenas, 1990, p. 309)

Arenas ha gritado; al hacerlo sirviéndose de su palabra, ha cumplido con el mandato del maestro. ${ }^{14}$ No obstante, su grito ha sido universal. Los roedores han mordido los cimientos de la dictadura y arañado con su comportamiento todo lo que semeje al poder. La voz opositora se ha alzado contra la arenga oficial; la colectividad ciudadana tutea al dictador de turno como desafío: "un pueblo permanece junto a su bestia a la hora de partir" (Piñera, 2000b, p. 49). En su ilusoria victoria, "el pueblo, tocado por la euforia de la fuga y por lo tanto de la libertad, comenzó a dar gritos de júbilo mientras que con las manos, cual si fueran remos, trataba de conducir la isla hacia puntos diferentes" [la cursiva es agregada] (Arenas, 1990, p. 436). El resultado es que, ante la imposibilidad de aceptar -o de entender- una pluralidad de opiniones, los habitantes de la Cuba dictatorial que conoció Arenas, mientras gozan de una exaltación desenfrenada "hasta saber el peso de su isla" (Piñera, 2000b, p. 49), hacen que desaparezca, metafóricamente, justo al tirano celebrar sus cincuenta años en el poder. A pesar de haber errado en su premonición apocalíptica, El color del verano es, en parte, el desdoblamiento discursivo de un verso que aspira, y logra, rendir un acertado encomio a un poema, y a su autor, que cien años después de su natalicio, sigue despertando inquietudes críticas por parte de sus lectores. Arenas ha probado saber copiar bien de sus lecturas y, a su vez, incorporar la voz de su profesor Piñera en agradecimiento por la prórroga que otorgó a su vida.

\section{Notas}

1. No pretendo cuestionar la autenticidad de la autobiografía de Arenas. Acepto su palabra como texto abierto y bajo la presuposición que no ha sido alterada por intereses ajenos o por las circunstancias. Recomiendo a los interesados en la materia, los enfoques de Bernard Schulz-Cruz, (1999), de Abilio Estévez, (1994), y, con detenimiento, el de Liliane Hasson (1994), especialmente donde la estudiosa francesa comenta detalles significativos sobre su revisión de la autobiografía de Arenas y su intervención en la edición príncipe, en español, llevada a cabo por Tusquets en 1992 (p. 119). Así se podrá acceder a otras aproximaciones críticas sobre Antes que anochezca, aunque, como sería de esperar, no son las únicas fuentes con que cuenta el lector.

2. Hay que tener en consideración que Arenas sacó sus manuscritos a escondidas, y "esto se consideró un acto subversivo, y desde entonces sus actividades fueron supervisadas cautelosamente por las fuerzas de la seguridad del estado" (Cacheiro, 2000, p. 125). Véase la siguiente nota.

3. Arenas hace mención del "gran éxito en Francia" (Arenas, 1992, p. 143) de El mundo alucinante. A su vez, hace referencia a Celestino antes del alba, su primera novela; esta última publicada en Cuba. Con el triunfo, arribaron los problemas: "fui puesto en la mirilla de Seguridad del Estado, ya no solo como un tipo conflictivo que había escrito novelas como El mundo alucinante o Celestino antes del alba, que eran textos irreverentes que no hacían apología al régimen (que más bien lo criticaban), sino que, además, había cometido la osadía de sacar, clandestinamente, aquellas obras" (Arenas, 1992, p. 143). 
Con relación al párrafo anterior, se podría traer a discusión que en una entrevista, es Arenas quien manifiesta que "ser escritor es una dicha o una fatalidad que está más allá de cualquier sistema social" (Rozencvaig, 1981, p. 48). El organismo que delata no lo conmina a producir, pero, paradójicamente, nutre su convicción.

4. La triple personalidad concebida por Arenas corresponde a otras tantas dimensiones en la vida del escritor. En cada una de ellas desarrolla una parte de su personalidad. En "Viaje a Holguín" (Arenas, 1990, pp. 100-105), define el propósito de cada faceta y para quién(es) asume cada identidad. Me refiero en específico al pasaje donde expone a su madre "para ti sigo siendo Gabriel, para aquellos que leen lo que escribo y que casi nunca puedo publicar soy Reinaldo, para el resto de mis amigos, con los cuales de vez en cuando me escapo para ser yo totalmente, soy la Tétrica Mofeta” (1990, p. 115). Aclaro este punto puesto que la dimensión correspondiente a la Tétrica Mofeta podría aparecer en algunos de los capítulos que catapultan los acápites del texto denominados 'historia'.

Insisto en recalcar que en El color del verano, Arenas concierta su ficción al transferir la historia de la isla a la de su personaje. La Tétrica Mofeta (que como se dijera es una de las tres dimensiones de sí mismo proyectadas por el autor-narrador) intenta completar el legajo de su existencia, manuscrito que siempre queda inconcluso por causa de algún accidente fortuito que lo obliga a recomenzar, a reinventar la epopeya de su vida; acto paralelo -simbólicamente hablando- a la necesidad de reescribir la fábula que se hace llamar oficial. Pero aquí la narración cobra una dimensión singular: se convierte en la personificación de una isla que a través de la palabra se corporiza para subvertirla

5. Es importante leer lo expuesto por Rafael Ocasio donde menciona que "Arenas took a clear position in the controversy over the importance of realism, either as the vehicle of a socialist realism attached to political activism within a revolutionary political platform, or as a step in developing newer literary trends within ideological parameters" (2003, p. 193). Ocasio basa su aserto en fragmentos de Celestino antes del alba, pero muy bien pudiera hacerse extensivo a El color del verano como totalidad donde el activismo político se fundamente en un texto en el que converjan diversas facetas de la realidad narrativa de Arenas.

6. Las novelas que componen lo que Arenas denomina la pentagonía son, por orden de publicación: Celestino antes del alba (1967), El palacio de las blanquísimas mofetas (1982), Otra vez el mar (1982), El color del verano (1991) y El asalto (1991). Nótese que El asalto, tal y como ocurriera con El color del verano, llegaron a la imprenta una vez fallecido su autor. Arenas se suicidó el 7 de diciembre de 1990. Consúltese el texto de Francisco Soto ya que el crítico entrega el primer estudio publicado en el que se enfrenta la pentagonía como entidad literaria y no como fragmentos de una obra mayor. Las cinco novelas aparecen enfocadas bajo diferentes puntos de vista, lo que brinda diferentes perspectivas y otras tantas posibilidades de aproximación a la obra estudiada. Véase la segunda parte del libro (1994, pp. 51-136) en la que el tema de la subversión es el eje central. Cabe destacar que ese no es el único tema abordado, pero sí se utiliza como factor repetitivo que engarza otros aspectos discutidos.

7. Obsérvese que el poema "La isla en peso" apareció publicado el mismo año del natalicio de Arenas.

8. Antes de comenzar este enfrentamiento textual entre El color del verano y "La isla en peso" deseo aclarar al curioso lector que no pretendo, bajo ningún concepto, realizar un estudio general de la novela de Arenas ni del poema de Piñera. Presupongo, tal vez erróneamente, que los lectores han leído ambos textos -insisto que este conocimiento sería beneficioso para ir directamente a la esencia de la idea que nos ocupa-. Mi único interés, en este empeño crítico, es sugerir un posible trazado entre ambas composiciones y apuntar hacia donde podría surgir una parte, refiriéndome principalmente a los capítulos en El color del verano donde se enfoca literalmente la historia, con un verso de Piñera incluido en su indispensable poema. Cualquier otra aproximación crítica, reconozco que ya muchas han sido exploradas en otros trabajos -incluso por mí mismo-, no cumple con el propósito de este ensayo y, por consiguiente, he optado por omitirla. Asimismo, a veces intento alejarme de la llamada bibliografía por excelencia sobre ambos autores para, de este modo, evitar espacios comunes y ofrecer una oportunidad a nuevas voces críticas que merecen ser escuchadas. Como sugerencia alterna, véanse en su totalidad las propuestas de Rita Molinero en "Arenas en el jardín de las delicias", para una lectura alterna de $E l$ color del verano y los artículos que aparecen en la bibliografía incluida sobre "La isla en peso". 
9. Otros capítulos son "Delación” (1990, pp. 244-245), "Muerte de Virgilio Piñera” (1990, pp. 346-349) y "La partida" (1990, p. 432). Cuenta, a su vez, con un trabalenguas (1990, p. 136).

10. Comité de Defensa de la Revolución, CDR. Organismos gubernamentales orientados a espiar a los ciudadanos y reportar, a las autoridades, de sus actividades.

11. El color del verano cuenta con cinco capítulos titulados "La historia”. Consúltense las páginas 123-124, 163-164, 204-205, 327 y 442.

12. Arenas trae a colación al dictador, una figura conocida en las letras hispanoamericanas. No obstante, la presencia de este personaje se torna aún más significativa al lector percatarse que el autor lo ha nombrado Fifo. De por sí, el nombre carece de mayor importancia ya que Fifo es un déspota que no solo rige el destino de todos los habitantes sino que participa en las actividades carnavalescas designadas a conmemorar, además de sus múltiples décadas de dominio, la llegada de un nuevo milenio -recuérdese que la trama de El color del verano se desarrolla en las postrimerías del siglo XX cubano-. Lo que sí es elocuente es que Arenas asigne este nombre al tirano; con anterioridad, su maestro literario, Piñera (2000a), lo había utilizado para designar a uno de los dobles del protagonista de su novela, La carne de René; mejor expresado aún: un muñeco. Para abundar en estos comentarios, recomiendo al estudioso que consulte el estudio de Francisco Soto, "El color del verano: innovaciones temáticas y aportaciones ideológicas a la novela del dictador" (1995), donde propone una lectura dentro del enmarque de la novela del dictador y con la característica de abordar también el tema homosexual como reto al poder. Aquí se analiza la proyección esperpéntica del dictador y su evolución dentro de la literatura latinoamericana. Al mismo tiempo, se convierte en una parada de rigor revisar la novela de Piñera, La carne de René, para cotejar el nombre de Fifo dado al doble: "Fifo es el doble de su otro yo" (2000a, p. 147) con el tirano de Arenas. Recomiendo, a su vez, a quienes se interesen en las posibilidades del doble como recurso estético, que consulten el trabajo de Carlos Cuadra (2012). Este ensayo forma parte de la bibliografía que clausura mi aproximación crítica.

13. Me refiero al ensayo de Arenas "La isla en peso con todas sus cucarachas" publicado en 1983, en la Revista Mariel [1 (2), 20-24] y reproducido en Necesidad de libertad. Cito por la edición de Universal (2001, pp. 131-152), sin embargo, es necesario recordar que la primera edición de Necesidad... corrió a cargo de la Kosmos-Editorial, en México, 1986. El ensayo en cuestión sigue siendo interés de editores; por ejemplo, Rita Molinero lo incluyó, en 2002, en su compendio sobre Piñera (pp. 29-48), texto mencionado en la bibliografía adjunta.

14. No deseo concluir esta lectura de El color del verano sin comentar que en el prólogo (1990, pp. 246-250), Arenas hace énfasis, además, en su grito de rebeldía, su privilegio de poder gritar. El autor expresa la posibilidad de encontrar un oído receptivo que capte -en beneficio de la humanidad- sus experiencias para la construcción de una sociedad mejor. Él subraya que "[t]al vez ese grito no caiga en el vacío. La esperanza de la humanidad está precisamente en aquellos que más han sufrido” (1990, p. 247). Asimismo, insiste en una de las características más notables en su vida y en su obra: la soledad del individuo. Hay que recordar que el poder concluir El color del verano -y de esta forma la pentagoníaproporcionó a Arenas las fuerzas suficientes para postergar su fin; le dio un sentido fundamental a su vida (1990, p. 250). Arenas admite estar solo, vivir solo y sufrir sus espantos solo (1990, p. 247). Todo el discurso textual de El color del verano -con explicitud demostrado en el prólogo-conduce hacia la destrucción del autor, el fin es inevitable.

\section{Bibliografía}

Abreu, J. (1998). A la sombra del mar: jornadas cubanas con Reinaldo Arenas. Barcelona: Casiopea.

Abreu-Felippe, N. (2001). Mi amigo Reinaldo Arenas. Por L. De la Paz (Ed.). Reinaldo Arenas, aunque anochezca. (184-193). Miami: Universal.

Arenas, R. (1983). La isla en peso con todas sus cucarachas. Mariel. 1 (2), 20-24. 
Arenas, R. (1990). El color del verano. Miami: Universal.

Arenas, R. (1992). Antes que anochezca. Barcelona: Tusquets.

Arenas, R. (2001). Necesidad de libertad. Miami: Universal.

Arenas, R. (2002). La isla en peso con todas sus cucarachas. Por R. Molinero (Ed.). Virgilio Piñera. La memoria del cuerpo. (29-48). San Juan: Plaza Mayor.

Arrufat, A. (2002). Un poco de Piñera. Por R. Molinero (Ed.). Virgilio Piñera. La memoria del cuerpo. (49-77). San Juan: Plaza Mayor.

Cabrera-Infante, G. (1974). Vista del amanecer en el trópico. Miami: Universal.

Cabrera-Infante, G. (1999). Mea Cuba. Madrid: Alfaguara.

Cacheiro, A. (2000). Reinaldo Arenas: una apreciación politica. Lanham, MD: International Scholars Publications.

Cuadra, C. (2012). La delectación morosa en La carne de René, de Virgilio Piñera. Por H. López-Cruz (Ed.). Virgilio Piñera: el artificio del miedo. (322-351). Madrid: Editorial Hispano Cubana.

De Feo, M.Á. (2012). La celebración del hereje: Cuba sin atributos en 'La isla en peso' de Virgilio Piñera. Por H. López-Cruz (Ed.). Virgilio Piñera: el artificio del miedo. (213238). Madrid: Editorial Hispano Cubana.

Eco, U. (1984). The Role of the Reader. Bloomington: Indiana University Press.

Esteso-Martínez, S. (2002). Carnaval y homoerotismo. Reinaldo Arenas: el color de los sentidos. Por E. Varcárcel (Ed.). La literatura hispanoamericana con los cinco sentidos. V congreso internacional de la AEELH. (211-220). A Coruña: Universidade da Coruña.

Estévez, A. (1994). Between Nightfall and Vengeance: Remembering Reinaldo Arenas. Michigan Quarterly Review. 33 (4), 859-867.

Ette, O. (1992). Los colores de la libertad. Nueva York, 14 de enero de 1990 [entrevista]. Por O. Ette (Ed.). La escritura de la memoria. (75-91). Frankfurt: Vervuert.

Flores, B. (2008). La retórica de la autobiografía en Antes que anochezca. Por M.T. Miaja de la Peña (Ed.). Del alba al anochecer. La escritura en Reinaldo Arenas. (127143). México, Madrid y Frankfurt: Universidad Nacional Autónoma de México/ Iberoamericana/Vervuert.

Hasson, L. (1994), Reinaldo Arenas, Francia y El libro de las flores. Por R. Sánchez (Ed.). Reinaldo Arenas: recuerdo y presencia. (109-119). Miami: Universal.

Jambrina, J. (2012). Virgilio Piñera: poesía, nación y diferencias. Madrid: Verbum.

Jiménez, L.A. (2012). ¿Es 'La isla en peso' una escritura antiestética de la cubanía? Por H. López-Cruz (Ed.). Virgilio Piñera: el artificio del miedo. (192-212). Madrid: Editorial Hispano Cubana.

López-Cruz, H. (Ed.). (2012). Virgilio Piñera: el artificio del miedo. (192-212). Madrid: Editorial Hispano Cubana. 
Molinero, R. (1994). Arenas en el jardín de las delicias. Por R. Sánchez (Ed.). Reinaldo Arenas: recuerdo y presencia. (129-137). Miami: Universal.

Molinero, R. (Ed.). (2002). Virgilio Piñera. La memoria del cuerpo. San Juan: Plaza Mayor.

Ocasio, R. (2003). Cuba's Political and Sexual Outlaw: Reinaldo Arenas. Gainesville: University Press de Florida.

Piñera, V. (2000a). La carne de René. Barcelona: Tusquets.

Piñera, V. (2000b). "La isla en peso". La isla en peso. Obra poética. (37-49). Barcelona: Tusquets.

Quintero-Herencia, J. C. (2012). Paisajes digestivos, islas interpuestas: Poéticas y políticas de Luis Palés Matos y Virgilio Piñera. Caribe abierto: ensayos críticos. (197-224). Pittsburgh: Instituto Internacional de Literatura Iberoamericana.

Rojas, R. (2002). Newton huye avergonzado. Por R. Molinero (Ed.). Virgilio Piñera. La memoria del cuerpo. (249-259). San Juan: Plaza Mayor.

Rozencvaig, P. (1981). Reinaldo Arenas, entrevista. Hispamérica. 10 (28), 41-48.

Schulz-Cruz, B. (1999). Antes que anochezca: el exorcismo de Arenas. Por R. Sánchez y H. López- Cruz (Eds.) Ideología y subversión: otra vez Arenas. [A. Pérez-Alencart, epílogo]. (51-61). Salamanca: CEIAS: Centro de Estudios Ibéricos y Americanos de Salamanca.

Soto, F. (1994). Reinaldo Arenas. The Pentagonía. Gainesville: University Press of Florida.

Soto, F. (1995). El color del verano: innovaciones temáticas y aportaciones ideológicas a la novela del dictador. Apuntes Posmodernos. 6 (1), 59-65.

Weintraub, K. J. (1991). Autobiografía y conciencia histórica. (A.M. Dotras, tr). Anthropos 29, $18-33$

Winks, C. (2008). La isla a la deriva, con sus caras y sus culos. Lo tardío transgresor en El color del verano. Por M.T. Miaja de la Peña (Ed.). Del alba al anochecer. La escritura en Reinaldo Arenas. (103-116). México, Madrid y Frankfurt: Universidad Nacional Autónoma de México/Iberoamericana/Vervuert. 